\title{
Planetary albedo in strongly forced climate, as simulated by the CMIP3 models
}

\author{
Frida A-M. Bender
}

Received: 15 September 2010 / Accepted: 24 January 2011 / Published online: 11 February 2011

(C) The Author(s) 2011. This article is published with open access at Springerlink.com

\begin{abstract}
In an ensemble of general circulation models, the global mean albedo significantly decreases in response to strong $\mathrm{CO}_{2}$ forcing. In some of the models, the magnitude of this positive feedback is as large as the $\mathrm{CO}_{2}$ forcing itself. The models agree well on the surface contribution to the trend, due to retreating snow and ice cover, but display large differences when it comes to the contribution from shortwave radiative effects of clouds. The "cloud contribution" defined as the difference between clear-sky and all-sky albedo anomalies and denoted as $\triangle C C$ is correlated with equilibrium climate sensitivity in the models (correlation coefficient 0.76 ), indicating that in high sensitivity models the clouds to a greater extent act to enhance the negative clearsky albedo trend, whereas in low sensitivity models the clouds rather counteract this trend. As a consequence, the total albedo trend is more negative in more sensitive models (correlation coefficient 0.73 ). This illustrates in a new way the importance of cloud response to global warming in determining climate sensitivity in models. The cloud contribution to the albedo trend can primarily be ascribed to changes in total cloud fraction, but changes in cloud albedo may also be of importance.
\end{abstract}

\section{Introduction}

The global mean albedo of the Earth appears to have been remarkably stable over time. Observations

F. A-M. Bender $(\bowtie)$

Scripps Institution of Oceanography,

University of California, San Diego,

La Jolla, CA 92093, USA

e-mail: fbender@ucsd.edu by satellite-borne radiometers of the global planetary albedo have only been available for the past few decades, but these short-term observations of albedo indicate a stability of the global annual mean albedo around $0.29 \pm 0.01$ (Bender et al. 2006). Longerterm albedo stability can be indirectly deduced from the relative stability of the instrumental temperature record prior to the satellite era. As given by Eq. 1, the global mean albedo is a primary determinant of the Earth's radiative temperature and thereby the surface temperature. The variability in global mean albedo can be related to variability in global mean radiative temperature,

$\frac{S_{0}}{4}(1-\alpha)=\sigma T_{\text {eff }}^{4}$.

Here $S_{0}$ is the incoming solar flux at the top of the atmosphere (TOA), $\alpha$ is the planetary albedo, $\sigma$ is the Stefan-Boltzmann constant, and $T_{\text {eff }}$ is the Earth's effective radiative temperature. Hereby, a $1-\mathrm{K}$ variation in $T_{\text {eff }}$ corresponds to a 0.01 variation in albedo. The $1-\mathrm{K}$ variation in surface temperature $\left(T_{\mathrm{s}}\right)$, seen over the late Holocene (Moberg et al. 2005), suggests even smaller albedo variability according to, e.g., Cahalan et al. (1994), who estimates that a surface temperature change of $1 \mathrm{~K}$ corresponds to a relative albedo change of $2 \%$, i.e., an absolute bias of ca. 0.006 .

Hence, there seem to be feedbacks operating to keep the albedo stable, but identification and quantification of these feedbacks are still open questions. A related and equally open question is if these feedbacks remain unchanged in a changing climate. This study therefore investigates how the albedo stability is affected by strong $\mathrm{CO}_{2}$ forcing in global climate models and also attempts to attribute the modeled albedo changes to 
variations in surface albedo and variations in cloud properties, respectively.

\section{Models}

For the analysis of albedo trends in forced climate simulations, CMIP3 model output is used. CMIP3 refers to the World Climate Research Programme's Coupled Model Intercomparison Project phase 3 (CMIP3) multi-model data set (Meehl et al. 2007), originally developed in support of the IPCC 4th Assessment Report.

Simulations of the twentieth century climate (ending in 1999) that include forcing from anthropogenic greenhouse gases (GHGs), atmospheric aerosols, solar variability, etc. according to available historical data and simulations where the $\mathrm{CO}_{2}$ concentration increases by $1 \%$ per year for ca. 150 years, up to a quadrupled concentration, and is then held constant are studied. These strongly forced simulations, referred to as 1 pctto4x, are not available for all CMIP3 models. Also, some models with 1 pctto $4 \mathrm{x}$ simulations do not supply all radiative flux parameters necessary for the trend analysis conducted, and therefore in Section 3, only a subset of the models are utilized. These models and their spatial resolutions are listed in Table 1.

For albedo calculation from model output monthly means of incoming and reflected shortwave (SW) radiative fluxes at the TOA are used. Further, the model parameter "total cloud fraction" is used in the analysis. This value is a result of different cloud overlapping schemes in different models, but regardless of the cloud overlap algorithm, the parameter total cloud fraction is what in each model is seen from above or below.

\section{Results}

3.1 Global albedo in strongly forced climate models

In simulations of the twentieth century, including forcing from both increasing GHG concentrations and aerosols, all 20 CMIP3 models studied show an albedo variability within $\pm 5 \mathrm{E}-3$, or ca. $2 \%$ (not shown). The surface albedo decreases in all models, but this trend is counteracted by increased reflection from increasing sulfate aerosol loading during the past century. In models including parameterizations of volcanic eruptions, the late twentieth century albedo trend is in most cases particularly positive due to the positive anomalies caused by the volcanic aerosol.

To exclude interference from aerosols and isolate and emphasize the effect of increased $\mathrm{CO}_{2}$ concentration, simulations where the aerosol loading is kept constant at a pre-industrial or present-day level and the $\mathrm{CO}_{2}$ concentration is increased by $1 \%$ per year to a quadrupling are considered. Note the present day increase of $\mathrm{CO}_{2}$ concentration of ca. $0.5 \%$ per year.

As seen in Fig. 1, all studied models show a decreasing global mean albedo, i.e., a positive feedback in response to the forcing. In one model (GISS-ER), the negative albedo trend is reversed during the $\mathrm{CO}_{2}$ increase, before leveling out. The magnitude of the trend varies significantly among models and reaches

Table 1 Models used in the present study and their origin and atmospheric resolution (corresponding to the Gaussian grid on which the atmospheric output is delivered)

\begin{tabular}{|c|c|c|}
\hline Modeling group(s) & Model name & Atm. res. \\
\hline Canadian Centre for Climate Modelling and Analysis, Canada & CGCM3.1 & $3.8 \times 3.8^{\circ}, \mathrm{L} 31$ \\
\hline $\begin{array}{l}\text { Meteo-France, Centre National de Recherches Meteorologiques, } \\
\text { France }\end{array}$ & CNRM-CM3 & $2.8 \times 2.8^{\circ}, \mathrm{L} 45$ \\
\hline US Department of Commerce/NOAA/Geophysical Fluid Dynamics & GFDL-CM2.0 & $2.5 \times 2.0^{\circ}, \mathrm{L} 24$ \\
\hline Laboratory, USA & GFDL-CM2.1 & $2.5 \times 2.0^{\circ}, \mathrm{L} 24$ \\
\hline NASA/Goddard Institute for Space Studies, USA & GISS-ER & $3.9 \times 5.0^{\circ}, \mathrm{L} 20$ \\
\hline Institute for Numerical Mathematics, Russia & INM-CM3.0 & $5.0 \times 4.0^{\circ}, \mathrm{L} 21$ \\
\hline Institut Pierre Simon Laplace, France & IPSL-CM4 & $3.8 \times 2.5^{\circ}, \mathrm{L} 19$ \\
\hline $\begin{array}{l}\text { Center for Climate System Research (The University of Tokyo), } \\
\text { National Institute for Environmental Studies, and Frontier } \\
\text { Research Center for Global Change (JAMSTEC), Japan }\end{array}$ & MIROC3.2(medres) & $2.8 \times 2.8^{\circ}, \mathrm{L} 20$ \\
\hline Max Planck Institute for Meteorology, Germany & ECHAM5/MPI-OM & $1.9 \times 1.9^{\circ}, \mathrm{L} 31$ \\
\hline Meteorological Research Institute, Japan & MRI-CGCM2.3.2 & $2.8 \times 2.8^{\circ}, \mathrm{L} 30$ \\
\hline National Center for Atmospheric Research, USA & CCSM3 & $1.4 \times 1.4^{\circ}, \mathrm{L} 28$ \\
\hline $\begin{array}{l}\text { Hadley Centre for Climate Prediction and Research/Met Office, } \\
\text { UK }\end{array}$ & UKMO-HadGEM1 & $1.9 \times 1.3^{\circ}, \mathrm{L} 38$ \\
\hline
\end{tabular}

More detailed model documentation can be found at the PCMDI-website (www-pcmdi.llnl.gov/ipcc/model_documentation/ipcc_model_ documentation.php) 


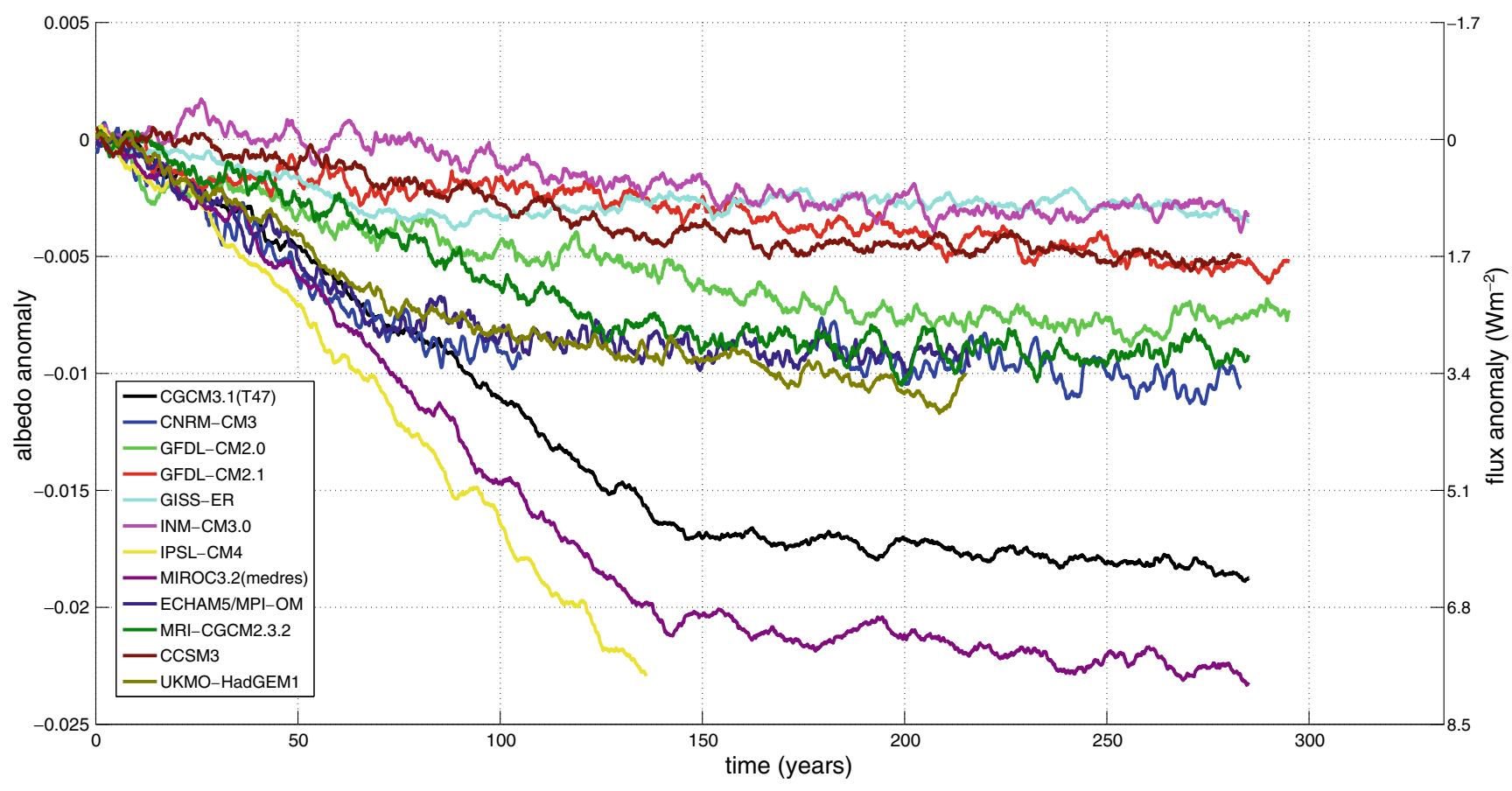

Fig. 1 Global mean TOA albedo anomaly in 12 models in a simulation with $1 \% \mathrm{CO}_{2}$ increase per year to quadrupling (1pctto4x). Values are given as de-seasonalized anomalies from a 10-year-long reference period and smoothed with a 5-year running mean

to as much as $1.6 \mathrm{E}-4$ per year in IPSL-CM4. Over 150 years (up to a quadrupling of the $\mathrm{CO}_{2}$ level), this leads to a decrease in global mean albedo of up to more than $2 \mathrm{E}-2$, corresponding to a ca. $7 \mathrm{~W} \mathrm{~m}^{-2}$ TOA SW flux anomaly (note that this transformation to radiative flux is done for global mean anomalies). For comparison, the direct radiative forcing from the quadrupling of $\mathrm{CO}_{2}$ is ca. $7.4 \mathrm{~W} \mathrm{~m}^{-2}$ (using $\Delta F=$ $5.35 \times \ln \left(c / c_{0}\right)$, where $\Delta F$ is the radiative forcing, $c$ is the $\mathrm{CO}_{2}$ concentration in parts per million by volume, and $c_{0}$ is the reference $\mathrm{CO}_{2}$ concentrations, as in Myhre et al. (1998)), and hence in the models with the largest albedo decrease, the magnitude of the positive albedo feedback is comparable to that of the initial forcing.

Apparently, the pre-industrial albedo stability can be disturbed by sufficiently strong $\mathrm{CO}_{2}$ forcing. And presumably, as the importance of aerosol decreases relative to that of GHG forcing (Dufresne et al. 2005), a negative albedo trend will also be seen in model simulations including varying levels of GHG and aerosol forcings. The decreasing albedo trend is seen to stabilize in all models, as the forcing, and the temperature change, stabilizes.

\subsection{Surface and cloud contribution to albedo trend}

A large part of the trend seen in the models is due to changes in surface properties, specifically retreat of snow and ice cover. Despite the spread in surface albedo among CMIP3 models in simulations of the twentieth century, documented by Roesch (2006), particularly for snow-covered regions, all models agree fairly well on the contribution from surface albedo changes to the total albedo trend. The surface albedo decreases in response to the quadrupling of $\mathrm{CO}_{2}$ are within $11 \mathrm{E}-3 \pm 5 \mathrm{E}-3$ for all models. The clearsky albedo changes, dominated by the surface albedo change, but also including an atmospheric contribution, show similar agreement in the model ensemble, with decreases of $9 \mathrm{E}-3 \pm 4 \mathrm{E}-3$. Given the slightly smaller drop and variability among models for clear-sky albedo than surface albedo, the atmospheric contribution to the reflection in most cases seems to dampen the surface albedo decrease and possibly also compensate for some spread among models.

The trend seen in the models is approximately linear during the period of increasing $\mathrm{CO}_{2}$ forcing, and there is no indication of accelerating albedo decrease due to ice albedo feedback. Changes in surface reflection are not sufficient to account for the whole trend seen in Fig. 1. In some models, the surface albedo trend exceeds the total albedo trend, and in other models, the total albedo decrease is more than twice as large as the surface albedo decrease. The same is true if changes in clear-sky albedo are used to approximate the changes in surface albedo. The remaining part of the trend and 
also the spread among models can be accounted for by clouds.

The effect of clouds on the radiation balance is commonly studied in terms of cloud radiative forcing (CRF) defined as

$$
\mathrm{CRF}=\left(F_{\mathrm{CS}}-F\right)-\left(Q_{\mathrm{CS}}-Q\right)
$$

where $F$ and $Q$ are the outgoing longwave (LW) and net SW (positive downwards) radiation at the TOA, respectively, and the subscript CS denotes clear-sky fluxes. The SW component of the CRF is

$\mathrm{CRF}_{\mathrm{SW}}=Q-Q_{\mathrm{CS}}=\frac{S_{0}}{4}\left(\alpha_{\mathrm{CS}}-\alpha\right)$,

where $\alpha$ is the all-sky albedo and $\alpha_{\mathrm{CS}}$ the clear-sky albedo. With this convention, $\mathrm{CRF}>0$ is equivalent to the presence of clouds having a warming effect.

The change in $\mathrm{CRF}(\triangle \mathrm{CRF})$ in response to a certain forcing has been used as an estimate of cloud feedback (e.g., Cess et al. 1990) and varies, even in sign, between models (Cess et al. 1990, 1996; Soden and Held 2006). As pointed out by Soden et al. (2004), the sign of $\triangle \mathrm{CRF}$ does not necessarily coincide with the sign of the cloud feedback, due to the masking effect of clouds on noncloud feedbacks, and even models with negative $\triangle \mathrm{CRF}$ can have a positive cloud feedback. There is, however, a correlation between $\triangle \mathrm{CRF}$ and cloud feedback, rendering also $\triangle \mathrm{CRF}$ a meaningful measure of cloud response to radiative forcing (Soden and Held 2006).

Here, the effect of clouds is quantified by comparison of the change in total (all-sky) albedo anomaly with that in clear-sky albedo anomaly and study of the difference $\Delta \alpha_{C S}-\Delta \alpha$, where $\Delta$ represents deviation from the reference value. This quantity represents a "cloud contribution" to the albedo trend and will be referred to as $\triangle \mathrm{CC}$. It is noted that $\triangle \mathrm{CC}$ has the same sign as $\Delta \mathrm{CRF}_{\mathrm{SW}}$, but that the two quantities differ by the factor $S_{0} / 4$. Figure 2 shows the temporal evolution of $\triangle \mathrm{CC}$ during the strongly forced $1 \mathrm{pctto} 4 \mathrm{x}$ simulations.

When $\triangle \mathrm{CC}$ is positive, the effect of including clouds enhances the negative (clear-sky or surface) albedo trend, indicating a positive $\triangle \mathrm{CRF}_{\mathrm{SW}}$, or that cloud reflection decreases. When $\triangle \mathrm{CC}$ is negative, the effect of including clouds counteracts the negative (clearsky or surface) albedo trend, indicating a negative $\triangle \mathrm{CRF}_{\mathrm{SW}}$, due to either that cloud reflection increases or that clouds are able to mask or hide part of the surface trend. The latter will be the case if areas with decreasing surface albedo are to a large extent covered by clouds.

$\triangle \mathrm{CC}$ can be ascribed to changes in cloud cover and/or cloud albedo, the latter to which the cloud

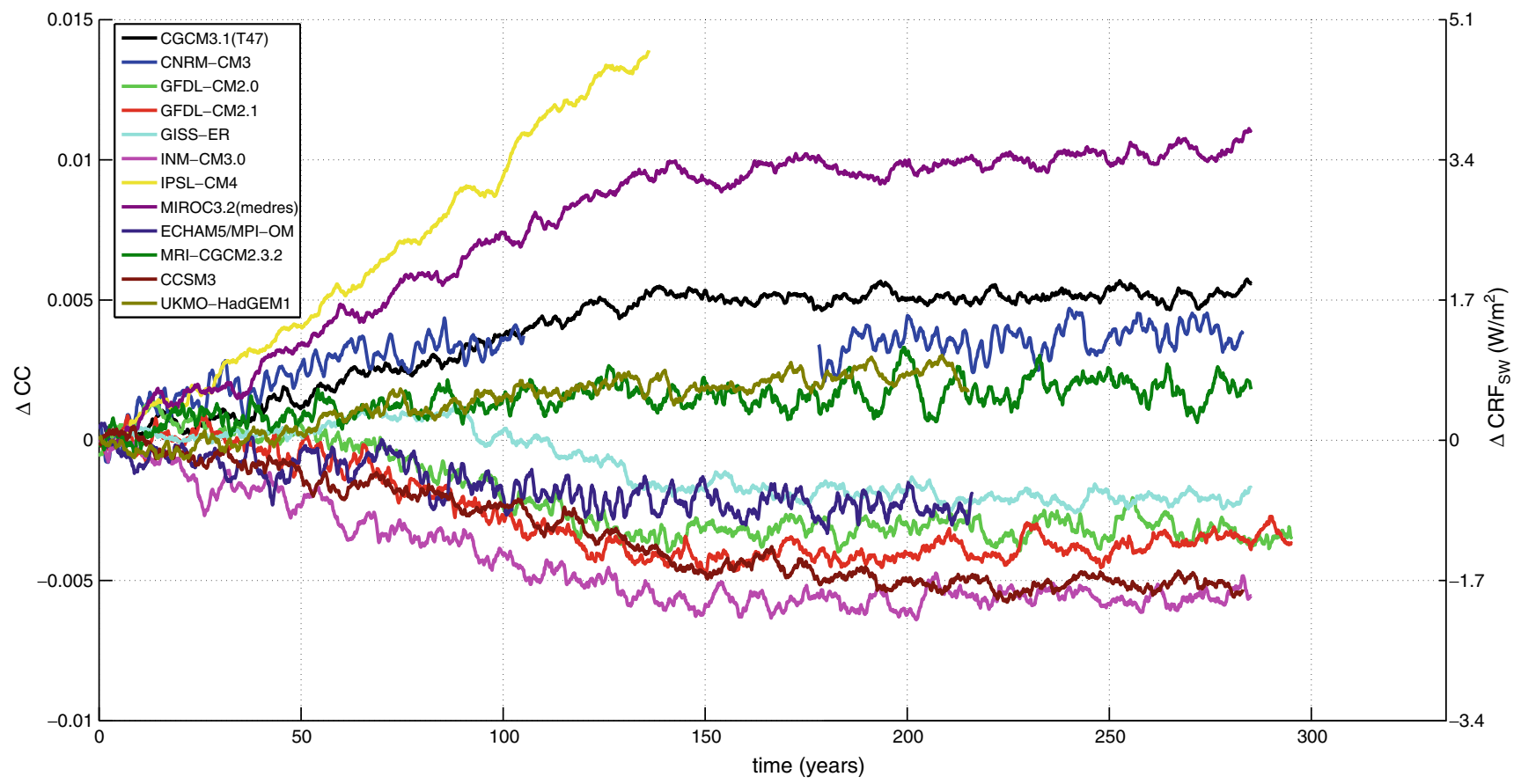

Fig. 2 The cloud contribution to the albedo trend, $\Delta \mathrm{CC}$, in the 1 pctto $4 \mathrm{x}$ simulations, i.e., the difference between anomalies (from a 10-year reference period) in global mean clear-sky albedo and global mean TOA albedo. The corresponding values of $\triangle \mathrm{CRF}_{\mathrm{SW}}$ are indicated as well. The time series are smoothed using a 5-year running mean 


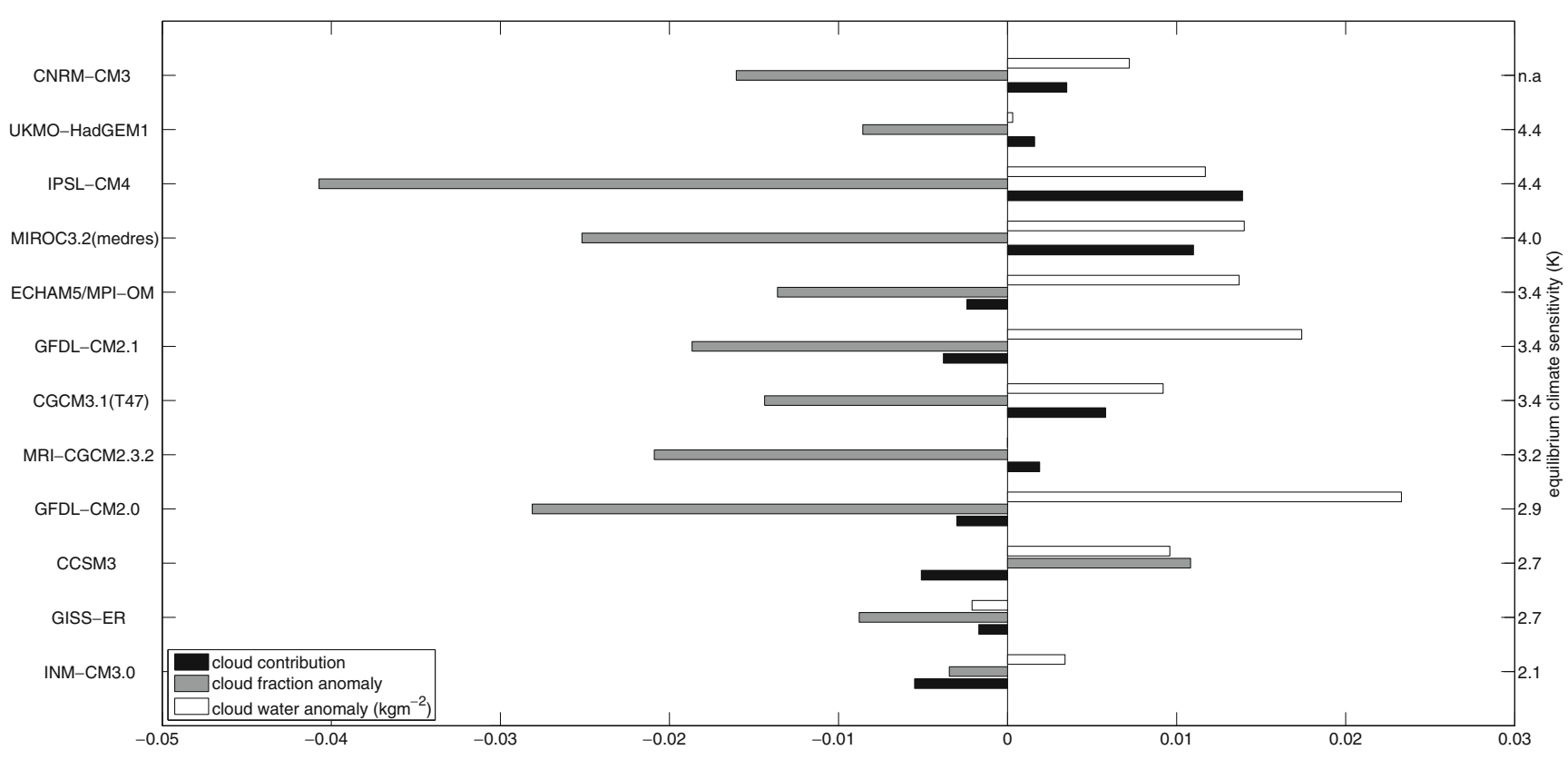

Fig. 3 Cloud contribution, $\triangle \mathrm{CC}$, at the end of the 1 pctto4x simulations (black bars), anomaly in global mean total cloud cover at the end of the 1pctto4x simulations (gray bars), and anomaly in global mean total cloud water content at the end of the 1pctto4x simulation (white bars). Cloud water content not available for MRI-CGCM2.3.2. Models are sorted by increasing equilibrium climate sensitivity $\left(\Delta T_{2 \times \mathrm{CO}_{2}}\right)$, except for CNRMCM3 for which $\Delta T_{2 \times \mathrm{CO}_{2}}$ is not available. The scale on the $x$-axis represents cloud contribution, cloud fraction anomaly, and cloud water anomaly (kilograms per square meter), respectively water content should be a primary contributing factor (Ramaswamy and Chen 1993). To coarsely estimate how these factors contribute to $\triangle \mathrm{CC}$, the global mean total cloud fraction and global mean total cloud water (liquid + ice) content in the models are used. Figure 3 shows the anomaly in total cloud fraction and in total cloud water (liquid and ice) at the end of the 1pctto4x simulations (the models are here sorted by climate sensitivity, as further discussed in Section 3.4). While most models show a decreasing total cloud fraction throughout the simulation, the cloud fraction in CCSM3 increases throughout and in CGCM3.1(T47) and INM-CM3.0 increases at first and then decreases. For global mean cloud water content, most models show an increase due to the $\mathrm{CO}_{2}$ forcing. One model (UKMO-HadGEM1) shows no change in cloud water content, and in one model (GISS-ER), the cloud water content slightly decreases at first and then returns to its initial level. This seems to be the cause of the changing signs of the albedo trend and cloud contribution for GISS-ER (Figs. 1 and 2) during the course of the simulation.

\subsection{Relations among cloud parameters}

There is a certain agreement between change in total cloud cover and $\triangle \mathrm{CC}$ among the models, models with larger decrease in total cloud cover having a more positive $\triangle \mathrm{CC}$ (correlation coefficient 0.69). In some models, however (GFDL-CM2.0, GFDL-CM2.1, and ECHAM/MPI-OM), the cloud fraction actually decreases while $\triangle \mathrm{CC}$ is negative, as seen in Fig. 3. This may be explained by changes in partitioning of the fractional cloud cover, making some regimes with certain cloud albedo more common at the expense of others. Ringer et al. (2006) study the cloud response to increased $\mathrm{CO}_{2}$ concentration in some of the CMIP3 models in more detail, using ISCCP cloud classifications, and find that the amount of thick clouds (with high optical depths and thereby albedos) increases in many models, whereas the amounts of thin and medium thick clouds (with lower optical depths and albedos) show more decreasing in response to increased $\mathrm{CO}_{2}$ forcing, which can be in agreement with negative $\triangle \mathrm{CC}$ despite decreasing total cloud fraction. Cloud data to expand such analysis to include the models of the present study are not available in the CMIP3 data archive.

There is no apparent relation between change in cloud water content and $\triangle \mathrm{CC}$ in the models, but this can be due to that cloud albedo changes arise from changes in the distribution of water within the cloud, the cloud drop size distribution, and the partitioning between water and ice, rather than the condensed water content. 


\subsection{Relations with climate sensitivity}

The magnitude of the global mean albedo decrease in the strongly forced simulations is correlated with equilibrium climate sensitivity $\Delta T_{2 \times \mathrm{CO}_{2}}$ of the studied models $\left(\Delta T_{2 \times \mathrm{CO}_{2}}\right.$ is defined as the equilibrium increase in global mean surface temperature after an instantaneous doubling of $\mathrm{CO}_{2}$ and calculated using the atmospheric part of the model, coupled to a slab ocean). The albedo hence decreases more in more sensitive models, and the correlation coefficient for this relation is 0.73 for 11 of the models shown in Fig. 1 (equilibrium climate sensitivity for CNRM-CM3 is not available).

There is also a correlation between equilibrium climate sensitivity and the magnitude of $\triangle \mathrm{CC}$, as higher sensitivity models tend toward larger (positive) values of $\triangle \mathrm{CC}$ and lower sensitivity models tend toward smaller (negative) values. This is reasonable; in highsensitivity models, the clouds tend to enhance or amplify the warming negative clear-sky albedo trend with a positive $\triangle \mathrm{CRF}_{\mathrm{SW}}$, and in low-sensitivity models, the clouds on the contrary counteract the negative clearsky/surface albedo trend with a negative $\Delta \mathrm{CRF}_{\mathrm{SW}}$. The correlation coefficient is 0.76 for 11 models. This is also in agreement with the results of Cess et al. (1990) and supports the conclusion of that and other studies (e.g., Soden and Held 2006; Dufresne and Bony 2008) that differences in climate sensitivity are driven mostly by differences in cloud feedback or response to the warming. Focusing on the albedo, the LW effect of clouds are disregarded. These must be included in a complete analysis of cloud feedbacks, but apparently the differences in climate sensitivity are to a large extent driven by differences in the SW component of the CRF, which is also in agreement with the results of Ringer et al. (2006).

Figure 3 shows $\triangle \mathrm{CC}$ at the end of the $1 \mathrm{pctto} 4 \mathrm{x}$ simulations in the models, sorted by the model climate sensitivity. Neither cloud water content changes, surface albedo changes nor cloud cover changes are sufficient to explain the apparent correlation between the total albedo reduction and the climate sensitivity in the models. Of these three quantities, the change in cloud fraction is best correlated with climate sensitivity, with a correlation coefficient of 0.56 ( $95 \%$ significant), while cloud water and surface albedo changes give correlation coefficients smaller than 0.2.

\subsection{Relative contribution to $\Delta \mathrm{CC}$}

To make a crude quantification of the relative importance of cloud albedo and cloud fraction to the change in $\mathrm{CRF}_{\mathrm{SW}}$ at the end of the $1 \mathrm{pctto} 4 \mathrm{x}$ simulation, Eq. 3 is used in combination with the expression

$\alpha=\alpha_{\text {cloud }} \times f+\alpha_{\mathrm{CS}} \times(1-f)$,

describing the dependence of total albedo $(\alpha)$ on cloud fraction $(f)$, cloud albedo $\left(\alpha_{\text {cloud }}\right)$, and albedo for clear sky $\left(\alpha_{\mathrm{CS}}\right)$ (Cess 1976), assuming that clear and cloudy skies can be distinguished.

This yields

$\Delta \mathrm{CRF}_{\mathrm{SW}}=\frac{S_{0}}{4}\left(\alpha_{\text {cloud }} \times f-\alpha_{\text {cloud }}^{\prime} \times f^{\prime}-\alpha_{\mathrm{CS}}\left(f-f^{\prime}\right)\right)$

where $f^{\prime}$ and $\alpha_{\text {cloud }}^{\prime}$ indicate the perturbed values for cloud fraction and cloud albedo respectively, assuming that $\alpha_{\mathrm{CS}}$ and $Q_{\mathrm{CS}}$ remain unchanged.

In the model ensemble mean, the global mean cloud fraction decreases from $65 \%$ to $63 \%$ over the course of the simulations. With an unchanged $\alpha_{\text {cloud }}$ of 0.4 , this change in cloud fraction then results in a $\triangle \mathrm{CRF}_{\mathrm{SW}}$ of $2 \mathrm{~W} \mathrm{~m}^{-2}$. A similar $\Delta \mathrm{CRF}_{\mathrm{SW}}$ results from a drop in $\alpha_{\text {cloud }}$ from 0.4 to 0.39 , with a constant cloud fraction of $65 \%$, and letting both cloud fraction and cloud albedo vary within these bounds gives a $\triangle \mathrm{CRF}_{\mathrm{SW}}$ of ca. $4 \mathrm{~W} \mathrm{~m}^{-2}$. These numbers are comparable to the $\triangle \mathrm{CC}$ and $\triangle \mathrm{CRF}_{\mathrm{SW}}$ values presented in Section 3.1 and indicate that a subtle change in cloud albedo alone, with constant cloud fraction, may account for $50 \%$ of the total change in $\mathrm{CRF}_{\mathrm{SW}}$ or $\triangle \mathrm{CC}$.

\section{Discussion and conclusions}

The apparent stability of the planetary albedo in past and present climate can be disturbed if the climate is strongly forced by increasing concentration of $\mathrm{CO}_{2}$. In simulations with 12 CMIP3 models, with the $\mathrm{CO}_{2}$ concentration increasing by $1 \%$ per year, the all-sky TOA albedo decreases in all cases, constituting a positive feedback of varying magnitude. In all models, the albedo trend stabilizes as the forcing and the temperature trend stabilize, but at the time of doubling (or quadrupling) of the $\mathrm{CO}_{2}$ concentration, the albedoinduced feedback in some of the models is comparable in magnitude to the initial $\mathrm{CO}_{2}$ forcing.

In simulations of the present-day climate, a $\mathrm{CO}_{2}$ induced albedo trend is not as clear, due largely to the counteracting effect of aerosols. Presumably, as aerosol significance decreases relative to that of GHG forcing, the negative trend in albedo will become more distinct.

The models agree well on the magnitude of the surface albedo contribution to the albedo trend, due 
to retreating snow and ice cover, but differ in their estimates of what is here called the cloud contribution, $\triangle C C . \Delta C C$ is defined as the difference between clearsky and all-sky albedo anomalies and has the same sign as the change in SW cloud radiative forcing, $\triangle \mathrm{CRF}_{\mathrm{SW}}$.

The magnitude of $\triangle \mathrm{CC}$ at the end of the strongly forced simulations is correlated with equilibrium climate sensitivity in the models (correlation coefficient 0.76) In models with high climate sensitivity, the cloud contribution enhances the negative albedo trend, i.e., there is a positive $\triangle \mathrm{CRF}_{\mathrm{SW}}$, and in models with low climate sensitivity, the cloud contribution counteracts the negative albedo trend, i.e., a negative $\triangle \mathrm{CRF}_{\mathrm{SW}}$, illustrating the importance of cloud feedback in determining climate sensitivity.

These sensitivity-related differences in cloud response to the forcing also cause the magnitude of the negative TOA albedo trend to be larger the higher the climate sensitivity of the model is (correlation coefficient 0.73 ). The cloud contribution to the albedo trend can in turn be attributed primarily to changes in cloud fraction, but also to changes in other cloud properties, specifically cloud albedo.

Acknowledgements This work was primarily performed while the author was at the Department of Meteorology, Stockholm University, Sweden. Helpful and constructive comments from Henning Rodhe and Annica Ekman are much appreciated. The modeling groups, the Program for Climate Model Diagnosis and Intercomparison (PCMDI) and the World Climate Research Programme's (WCRP's) Working Group on Coupled Modelling (WGCM), are acknowledged for their roles in making available the WCRP CMIP3 multi-model dataset. Support of this dataset is provided by the Office of Science, US Department of Energy.

Open Access This article is distributed under the terms of the Creative Commons Attribution Noncommercial License which permits any noncommercial use, distribution, and reproduction in any medium, provided the original author(s) and source are credited.

\section{References}

Bender FA-M, Rodhe H, Charlson RJ, Ekman AML, Loeb N (2006) 22 views of the global albedo-comparison between 20 GCMs and two satellites. Tellus A 58(3):320-330

Cahalan RF, Ridgway W, Wiscombe WJ, Bell TL, Snider JB (1994) The albedo of fractal stratocumulus clouds. J Atmos Sci 51:2434-2460
Cess RD (1976) Climate change: an appraisal of atmospheric feedback mechanisms employing zonal climatology. J Atmos Sci 33:1831-1843

Cess RD, Potter GL, Blanchet JP, Boer GJ, Del Genio AD, Déqué M, Dymnikov V, Galin V, Gates WL, Ghan SJ, Kiehl JT, Lacis AA, Le Treut H, McAvaney BJ, Meleshko VP, Mitchell JFB, Morcrette J-J, Randall DA, Rikus L, Roeckner E, Royer JF, Schlese U, Sheinin DA, Slingo A, Sokolov AP, Taylor KE, Washington WM, Wetherald RT, Yagai I (1990) Intercomparison and interpretation of climate feedback processes in 19 atmospheric general circulation models. J Geophys Res 95(D10):16,601-16,615

Cess RD, Zhang MH, Ingram WJ, Potter GL, Alekseev V, Barker HW, Cohen-Solal E, Colman RA, Dazlich DA, Del Genio AD, Dix MR, Esch M, Fowler LD, Fraser JR, Galin V, Gates WL, Hack JJ, Kiehl JT, Le Treut H, Lo KK-W, McAvaney BJ, Meleshko VP, Morcrette J-J, Randall DA, Roeckner E, Royer J-F, Schlesinger ME, Sporyshev PV, Timbal B, Volodin EM, Taylor KE, Wang W, Wetherald RT (1996) Cloud feedback in atmospheric general circulation models: an update. J Geophys Res 101(D8):12,791-12, 794

Dufresne J-L, Bony S (2008) An assessment of the primary sources of spread of global warming estimates from coupled atmosphere ocean models. J Climate 21:5135-5144

Dufresne J-L, Quaas J, Boucher O, Denvil S, Fairhead L (2005) Contrasts in the effects on climate of anthropogenic sulfate aerosols between the 20th and the 21st century. Geophys Res Lett 32:L21703

Meehl GA, Covey C, Delworth T, Latif M, McAvaney B, Mitchell JFB, Stouffer RJ, Taylor KE (2007) The WCRP CMIP3 multimodel dataset: a new era in climate change research. Bull Am Meteorol Soc 88:1383-1394

Moberg A, Sonechkin DM, Holmgren K, Datsenko NM, Karlén W (2005) Highly variable Northern Hemisphere temperatures reconstructed from low- and high-resolution proxy data. Nature 433:613-617

Myhre G, Highwood EJ, Shine KP, Stordal F (1998) New estimates of radiative forcing due to well mixed greenhouse gases. Geophys Res Lett 25:2715-2718

Ramaswamy V, Chen C-T (1993) An investigation of the global solar radiative forcing due to changes in cloud liquid water path. J Geophys Res 98:16703-16712

Ringer MA, McAvaney BJ, Andronova N, Buja LE, Esch M, Ingram WJ, Li B, Quaas J, Roeckner E, Senior CA, Soden BJ, Volodin EM, Webb MJ, Williams KD (2006) Global mean cloud feedbacks in idealized climate change experiments. Geophys Res Lett 33:L07718

Roesch A (2006) Evaluation of surface albedo and snow cover in AR4 coupled climate models. J Geophys Res 111: D15111

Soden BJ, Broccoli AJ, Hemler RS (2004) On the use of cloud forcing to estimate cloud feedback. J Climate 17:36613665

Soden BJ, Held IM (2006) An assessment of climate feedbacks in coupled ocean-atmosphere models. J Climate 19:33543360 